\title{
Interview
}

\section{In conversation with Desmond McGrath}

\section{David Healy interviewed Dr McGrath recently}

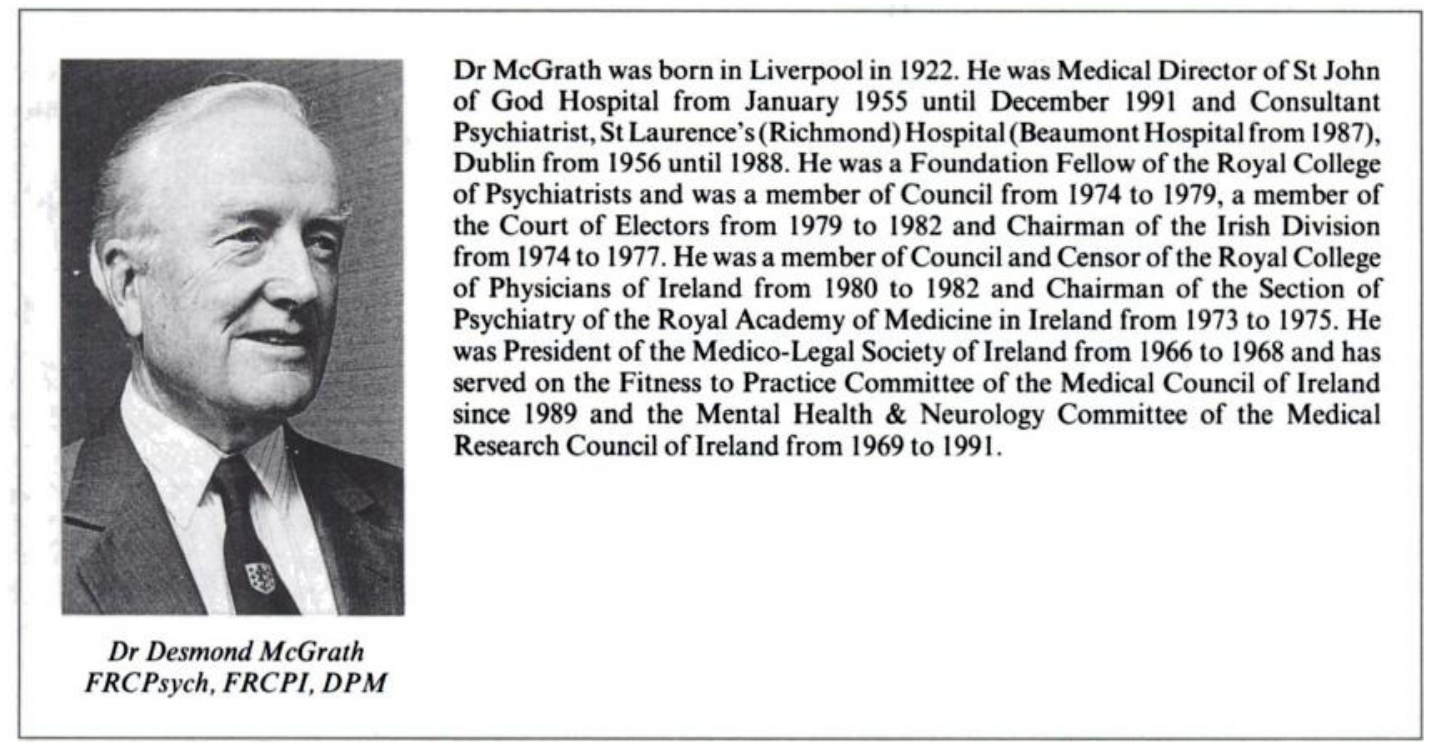

\section{How did you come to do psychiatry?}

I graduated from the Royal College of Surgeons Dublin in 1945 and I went to a house job in my teaching hospital, the Richmond. At that time I intended to do obstetrics but I had to wait for a post. I had a vague interest then in psychological matters, as most students had at some stage. I had read popular works such as Rudolph Aller's Psychology of Character.

So, after I finished in the Richmond I wanted to do my Membership. There was the matter of getting a roof over one's head, time to study, and to attend clinics and so on. These requirements and the fact that the local mental hospital, Grangegorman as it was then, offered a not too demanding job and a princely salary of $£ 100$ per year brought me there.

Grangegorman looked very grim and overcrowded when I saw it first in the late 1970s; what was it like at the end of the '40s?

It had improved vastly by the 1970s. In the 1940 s it was certainly grim and overcrowded but it had an essentially caring staff. There was very much a male-female divide and there was a distinct difference in the ambience of the female side, which was much cleaner and tidier. I got interested in psychiatry there. I was very impressed by the magical effect of ECT and, to a certain extent, insulin coma therapy. John Dunne, the Superintendent, later the first Professor of Psychiatry in Ireland and President of the RMPA, was a remarkable character. John was, in a sense, omnipresent. He had a kind of magisterial presence. Everything was done with the possibility of sworn enquiries if anything went wrong but also with the consideration of whether or not John would approve if he heard about it.

This atmosphere of everybody having to account for what they did and why they did it and having to go rigidly by the rules led to far too much restriction of individual liberty and an over-cautious approach to treatment and management. All the doors were securely locked and there were padded cells and so on. This gives a bad impression but it was not an unkindly regime.

It was an extraordinary place and many of the patients were extremely disturbed. We had to rely on barbiturates, bromides, and paraldehyde. There 
was also the cocktail of morphine and hyoscineguaranteed to knock out the most aggressive patient. ECT was a benefit because it controlled disturbed behaviour - not in a punitive way but by relieving the tremendous tension within some psychotic patients.

On the wards there were clinical clerks, assistant medical officers and senior medical offers. I was initially a clinical clerk and became an acting assistant medical officer. Each day you would get a batch of dockets. These were the statutory notes or records that had to be taken. A note had to be written every three months and later every six months and then every year on the patient's condition. You got a docket and then went round to the particular wards which you were covering. You'd just, in effect, say "hello" to the patients and ask about their eating habits or whether their bowels were regular or something like that. That was the statutory note. You tended to get out of the ward as quickly as you could and there were some wards where one only waved to the attendant. He would know who the patients were and he would indicate to you what the situation was. It was an appalling way to run a hospital. The female wards were as bad as the male.

You might ask was there any psychiatry in this but there was. These refractory wards were something apart really. They were looked on quite differently. There were also the admission wards and the treatment wards. The treatment wards, particularly the insulin ward, were quite good. I remember seeing one schizophrenic patient-a young female doctor - who came in very deluded. She made a remarkable recovery with ECT and insulin coma and later went back to practice and became a psychiatrist.

I remember that because it was a particularly dramatic example. But similar cases led one to think that one could achieve miracles. I'd been attracted to obstetrics in the first place, because it was a branch of medicine in which you saw immediate results. I must have held similar hopes of psychiatry because I remember later when I was being interviewed by Willy Mayer-Gross and P.K. McCowan for the Crichton Fellowship being asked the usual question, why had I chosen psychiatry, and innocently and naively replying, "Because I think you can do things for patients" - they smiled indulgently.

When I got my MRCPI I decided that it would be a good idea to get a background in neurology. I found that Queen's Square was the best place to go. I applied there and was accepted as a clinical clerk. I did six months there and studied at the same time for the DPM. The next problem was where to go in psychiatry. I was told, of course, that the Maudsley was the best place but that there was also a very good place in Scotland - the Crichton Royal.

By happy chance Crichton Royal advertised three fellowships in psychiatry. In those days this was an extraordinary idea for a mental hospital. These were just what would now be termed SHO jobs. The idea was that there should be doctors employed who were not AMOs or SMOs was virtually unique in mental hospitals at that time. So I applied for one and was accepted. I also applied for The Maudsley, the interview came up just after that and I was fortunate enough to be accepted too. In my naivety I thought that as I had accepted the Crichton first I had better go there. That was one of the most poorly reasoned but one of the best decisions I ever made.

I went to the Crichton in 1948 and met Willy Mayer-Gross. The Crichton opened up psychiatry to me. It was a wonderful time there-so astonishing that a remote hospital in the south of Scotland should have developed such an extraordinarily high standard of psychiatry. It was both a private hospital and the catchment hospital for the three surrounding counties.

Willy Mayer-Gross was a wonderful man. It would be hard to describe him. He was full of energy, vitality and enthusiasm and he was a very warm person. Once he thought you were keen he would encourage and guide you. He was a great teacher also and had tremendous contacts. All kinds of people came to Crichton to visit at that time. I remember meeting William Sargant, Aubrey Lewis, Pierre Pichot, Warren McCullagh, and many other famous figures.

Martin Roth was also working there. Martin would then have been the equivalent of senior registrar or young consultant. He was again a very good teacher and had a wonderful command of English. At case conferences we would run a book on the number of adjectives Martin would use when describing an individual patient.

But Willy Mayer-Gross also had his critical side. It was not all enthusiasm. On the whole he was very constructive in his criticism. One of the remarkable things about him was his written English. He had quite a distinct German accent when speaking but he thought so clearly that his written English was very good. He would encourage you to write a paper and you would give it to him for guidance on technical matters, advice on construction, or whatever. You'd get back your manuscript literally covered in thick blue pencil strokes and a few words here and there. When you'd examine it you would find that he had corrected your English and he would have stripped your diffuse account down to a bare couple of sentences. And it was expressed vastly better. This was a very good early lesson in how to write concisely.

He was writing his textbook at that time. We used to have formal lectures as well as the mostly clinical teaching. The formal lectures were in fact the early versions of the various chapters of the book.

He ran the Insulin Unit and we were absolutely convinced of its efficiency. I still have a feeling that 
there was something to insulin coma therapy despite Ackner's controlled trial which seemed to show that it was no better than placebo. I'm sure the fact that the patients were treated in an Insulin Unit called the Bungalow, were the elite patients in the hospital and got a tremendous amount of extra care, cossetting and support, had a lot to do with it all. It wasn't surprising that they got somewhat better results there.

We would try anything in those days, particularly for schizophrenia, because there were no specific treatments. I remember trying a drug called Malononitrile, which, according to a paper from the Karolinska Institute, increased the concentration of nucleoprotein in rabbit brains. We abandoned it when two patients had epileptic fits. We used electronarcosis as well as ECT. The most dramatic treatment, at least from the point of view of the treating doctor, was intravenous acetylcholine which caused the patient's heart and breathing to stop for 30 seconds. You stood by waiting for them to recommence I'm sure the psychological effect was greater on us than on the patient. Depression was not such a problem because ECT effectively managed it and, after all, those patients did, for the most part, get better in any event.

This isn't to say that it was all just purely physical treatment because they had a good department of social work and they also had a psychology department. The psychology department, as is so often the case, was heavily involved in research. Raven was the director. He didn't have much clinical input but his Progressive Matrices were used as a routine test. He used to give strange lectures starting, for example, "You may think that 2 and 2 make 4 but they don't necessarily. If there are 2 rabbits they very quickly become more than 4". I never quite grasped the point.

After I finished the year in Crichton I was worried in case I had lost my chance of getting to The Maudsley, but, particularly with Willy MayerGross's support, I was accepted there. I started in the neuropathology department with Professor Alfred Meyer. I had been interested in leucotomy which was a significant form of treatment in those days. By chance a patient who had done very well with a leucotomy at the Crichton had died. We managed to get the brain and sent it to Alfred Meyer. When I joined him I was able to study it and traced the degeneration of fibres. The work, although then considered very advanced, was crude by modern standards. In those days we naively believed that you might be able to demonstrate the actual centre of a disorder or the main influences on the disorder. We came incorrectly to the conclusion that the larger the damage to the dorsomedial nucleus of the thalamus, the better the prognosis. Subsequently, much more refined methods of neurosurgical intervention were devised.
I spent six months there and met Dennis Leigh, who was interested in neuropathological matters as well as being a proponent of Finesinger's non-directive psychotherapy. Years later we cooperated in organising a successful Regional Conference of the World Psychiatric Association in Dublin, when he was Secretary of that organisation.

Then there was Aubrey Lewis. I must say I was a great admirer of Aubrey. I found him intimidating but nevertheless kindly. I first met him when he was visiting Crichton Royal. We had heard from Martin Roth about Aubrey's 'terrorisation' of trainees and his eccentricities. So I had a picture of a rather intimidating individual. To my horror, particularly as I was hoping to go to The Maudsley, when I arrived down to breakfast in the Crichton one morning, I found myself alone with Aubrey, who had already started breakfast. He addressed me and asked me where I was from so I told him I was from Ireland. I had heard that he was interested in Ireland and of course this wasn't a bad thing to get in quickly but, again to my horror, he asked me something like "what view do you take of the social implications of the rising of 1916?". I had never thought very much about the social implications of 1916 and I made some trite reply, very much in trepidation. Aubrey then launched on the history of Ireland about which he was clearly a perceptive expert and so all went well. Some more people came down and my trial was over.

There were the usual terrifying experiences with Aubrey when you were presenting cases to him. Where he was possibly at his best was at the journal club meetings on Saturday mornings. The intense dissection and the acute analysis of what had seemed to be quite convincing papers was a very valuable experience.

I certainly don't accept the idea that Aubrey was purely negative and critical. He had an extraordinary group of people with diverse views around him. It was he who brought Clifford Scot there, Foulkes came and there was a whole range of schools represented.

Aubrey showed me a further kindness. Professor Bob Cleghorn from McGill had written to him looking for somebody interested in research to take up a Fellowship at McGill to work on the psychological aspects of fatigue in air crew in conjunction with studies of adreno-cortical function. Aubrey offered this to me and I very rapidly accepted. This was 1951 .

I got married at that point. In the same month that I started my married life I started working in Canada. I had met my wife in the Richmond. She was a student radiographer when I was a houseman. We had our first child in Montreal so Canada turned out to be happy from a personal as well as from the professional viewpoint. We were particularly fortunate in Montreal because Bob Cleghorn and his 
family became our friends and we had a very pleasant social as well as academic life.

It was very interesting being in Montreal at the time. Hans Selye was there. J.S.L. Brown was professor of medicine, a wonderful man, very comprehensive in his approach to medicine. He was essentially an endocrinologist but like many endocrinologists at that time, was very interested in psychosomatic aspects of medicine. I spent part of my time with him and I got involved in studying the psychological effects of treatment with cortisone and ACTH. There was a revolution going on in medicine at that time, a philosophical revolution, and J.S.L. Brown was one of the people who appreciated this.

\section{Why do you say that?}

Up to that time one tended to think of specific diseases and of specific methods of treatment such as antibiotics for bacterial diseases. This was a straightforward interaction. But with cortisone, for example, one is looking at a totally different arrangement $-\mathbf{a}$ full interaction and adaption of the body to stress. Our whole view of medicine was changing one didn't quite recognise it. But some individuals like J.S.L. Brown did and one picked it up from him and it inevitably affected your whole approach to medicine. Those were exciting times.

The Allen was undoubtedly the premiere psychiatric training centre in Canada and I think was well up the league on the North American continent. Robin Hunter, who later did so much to develop the Clark Institute in Toronto, and Tom Boag, who held a professorship in Kingston afterwards, were particular friends. Dongiere who had been with Gastaut in Marseilles, and who came back later to head up the Allen, was a resident at the time.

We had endless discussions on the world's problems and psychiatry's problems and longstanding friendships developed. The work that I was engaged on was very interesting. The measurements of adrenocortical function were then very crude.

We were working with urine samples and eosinophil counts in blood. First of all we had to establish our methods from the technical point of view and then we had to see if physical stress influenced those indices. We got air force personnel to take part in exercises in gymnastics to produce the effect of physical stress.

Then we flew with the Korean airlift which was being operated from Montreal in those days. We had to establish our methods to see if we could carry them out in the air. It was delightful in that it got us across the continent several times on trial and then to Tokyo during the US occupation which was a very interesting experience. Our plane packed up on this trip but unfortunately we were stranded on a remote Aleutian island rather than in Tokyo.
What actually was happening to our samples was obvious with hindsight but not so obvious in those days. It took us 72 hours or so to get to Tokyo. The problem was that there was a diurnal variation in corticoid secretion and we didn't know how to take it into account. We did not know whether to look at our results in terms of Montreal time or Tokyo time or somewhere in the middle. A real scientist would have seen the possible significance of what was happening. But we weren't prepared and we missed the fact that we had the underlying data for the prediction of "jet lag" many years before this phenomenon became recognised. Jets were just coming in at that time but not for passenger carrying planes. We did some work with jet fighter pilots later.

But we had all this material. The real researcher, the man who is going to make a breakthrough, spots the significance of what he has found but we were only upset by the fact that our particular experiments were not working out correctly.

When I was at McGill I had the opportunity of meeting many of the major people in psychiatry. Bob Cleghorn was well liked and he knew everybody. I went to various meetings with him. I was struck by the degree of informal interchange of information between research workers and the extensive knowledge they had of what was going on in each other's departments. This seemed in marked contrast to my experience in the much smaller UK.

Cortisone was so much part of the excitement of the time that many of the meetings centred on it. At that time quite a number of scientists and endocrinologists had undergone psychoanalysis and moved into psychosomatic medicine. At these conferences, particularly the Laurentien endocrinological conferences, which were exclusive and relatively informal, they used to have extraordinary fights - they were friendly but they were absolutely ruthless in their criticism of one another. This would be followed by disclaimers afterwards such as: "You may think I'm aggressive now, but you should have heard me before I was cured".

In North America they were at the height of the psycho-analytic era. You couldn't get any academic job in the North America unless you had been analysed - unless you were a card-carrying member of that society.

This was a problem for me because I hadn't been analysed. In The Maudsley some of my colleagues had been attracted to psychoanalysis but I didn't feel convinced enough to invest the time and money necessary to undergo a full scale analysis. My observation was, and still is, that of my colleagues who were analysed, the good ones went in as good psychiatrists and came out as good psychiatrists, possibly with extra sensitivity in psychotherapy, but the bad ones or odd ones came out just as odd. 
But in America psycho-analysis was supreme. I remember on one occasion going to a meeting of the Psychosomatic Society in Chicago. Franz Alexander, whose views on the psychodynamics of peptic ulceration and of duodenal ulceration in particular were taken as gospel, was giving a paper on the subject and it transpired that all of his observations were based on two patients - neither of whom had done well in therapy. Somebody else had at about the same time circulated all the members of the US Psychoanalytic Society to find out how many undertook analysis with patients suffering from peptic ulcer and what the results had been. There were only about three or four successful cases. For a remitting disorder this was not exactly encouraging.

When we came out after Alexander's paper I tried to provoke some of my enthusiastic colleagues by saying how this seemed to show that there was very little to his theory. But they were not the slightest bit perturbed. "Extremely interesting" and "needs further refinement" and so on was all they would concede.

But I was fortunate to have a great time in Montreal and to meet a number of interesting people. However, there came a point when both my wife and I wanted to come back to Ireland. The problem was how to get a position here. I certainly was not going into the public sector in an underfunded mental hospital system and there were no jobs of any consequence on the horizon except in St Patrick's. Norman Moore who was, in effect, pioneering psychiatry there, had promised that he would try to create one for me. He'd been in Crichton Royal like myself, years before, and he was attracted by the idea of research in psychiatry. He wanted to set up a post of Physician in Charge of Research. This would be a new development for St Patrick's, bringing in someone to do research at consultant level, and he had to convince his Board that this was a reasonable investment.

Norman Moore got the job cleared and I came back to Ireland to St Patrick's as Physician in Charge of Clinical Research in May 1954. At that time the drugs were just coming in. Willy Mayer-Gross had come back with news of chlorpromazine from France, and a treatment called 'hibernotherapy'. It was first used in anaesthetics for lowering temperature, hence the 'hiberno'. He suggested that we Irish would have a vested interest in it. In St Patrick's we started investigating chlorpromazine and reserpine. I liked reserpine except, unfortunately, for the depression it caused.

When I had been there only a few months and was still settling in with nothing dramatic emerging from my research efforts, the Brothers of St John of God advertised for a Medical Director at this hospital. The Brothers had decided at a conference which they had held in 1950 that there was a need for a child psychiatric service in Ireland-a child guidance service. They also at that conference decided that this hospital should be upgraded and that a Medical Director should be appointed here.

This hospital was then a small place with 135 beds in Stillorgan which was on the outskirts of Dublin with an admission rate of about 130 a year. It was run on nursing home principles with visiting consultants. They had a resident medical officer. While it didn't seem very inviting in many ways, it did present an opportunity and this was a time of great development in psychiatry. I made enquiries and found that the Brothers were really interested in transforming the place. They wanted to bring it up to top standard and they were also obviously planning major new developments, because at the same time they were getting the child psychiatric service going. They had already appointed John Stack and John McKenna to those posts. John McKenna, a psychologist, went to Montreal. I didn't know it at the time but he was at the University of Montreal while I was at McGill. It seemed that the post had possibilities. Having your own place and having the opportunity to develop as you wished was an attractive prospect and I got interested in it. So I talked it over with Norman because in a sense I was letting him down after he had gone to a great deal of trouble, but he, as always, was very decent and encouraging about it. He saw it was an opportunity for me and encouraged me to apply.

I was selected and started here on 1 January 1955. At the time patients were all male and the nursing was done almost exclusively by Brothers. I set about transforming it into an active treatment centre. The Brothers always ran it as a non-profit-making, private institution with very reasonable fees.

One of the difficult problems at the start was that in order to make room for the patients that one hoped to attract one had to find alternative accommodation for long-stay patients, and in particular psychogeriatric patients. That, of course, created financial problems. We had to work very hard to develop a clientele but it was exciting because it involved contacting doctors, giving talks to professional groups, and so on. This was generally beneficial as it led to a greater exposure of psychiatry, which was needed at the time.

I had a good relationship with Norman Moore although we were inevitably, to some extent, rivals. However, the benefits of cooperation vastly outweighed any rivalry and we both were fundamentally concerned with developing psychiatry in Ireland. We worked together in various ways. For example, when the Voluntary Health Insurance scheme was set up we went together to Noel Burke, who was chief executive of the VHI, and worked out terms for psychiatric patients with him which were vastly better than those with Blue Cross or any other existing insurance scheme. We put it to him that we both 
worked in non-profit-making hospitals and that our staff were salaried. We could guarantee top quality treatment and he would know exactly what his financial commitments were. He accepted this and agreed initially that the VHI would cover psychiatric patients for six weeks. After a short time we pushed him to three months and he, himself, because of his satisfaction, ultimately took off all restrictions on psychiatric patients. That is how things were for a long period until the recent cuts were instituted.

The Commission of Inquiry on Mental Illness was set up here in 1961 and reported in 1966. Norman Moore was appointed to it and so, incidentally, was Martin Roth. It seemed initially that consideration was going to be given only to the public sector. Norman asked how the private sector, which was in effect St Patrick's and St John of God Hospital, could be ignored when it dealt with approximately one third of all first admissions in the country even at that time. He was asked if he would be willing to cooperate in the development of public services and he assured them on the behalf of the two hospitals that he was.

I was anxious to do so because I could see that there was no future for a psychiatric hospital on its own - that you had to incorporate the other segments or aspects of psychiatry into a service that included the hospital. We worked on this and got agreement that in addition to their own services at $\mathrm{St}$ Patrick's and St John of God Hospital, each would take on a catchment area and provide a community psychiatric service for it. This plan was set up in 1971.

St John of God Hospital provides the in-patient beds for a catchment area with a population of over 180,000 . We don't make any distinction between private and public patients in regard to facilities and treatment. The only difference is that community service patients continue under the care of one particular consultant to whom they were originally referred. Possibly the most interesting concept in our community sector was the idea of 'family psychiatry' - not in the sense of family therapy but in terms of having child, adolescent and adult services under the one roof, integrated with one administration. We have, I think, succeeded in producing as good a community psychiatric service as one can under the dreadful restrictions that have been imposed by financial cut-backs.

Over the years there has been, in the public arena in Ireland, a somewhat sterile battle between the merits of hospital and community services. Any time we speak about it, it is assumed that we have to keep the hospital full of patients and therefore must take a biased view of the issues. That is not the case at all. Our view is simply that psychiatric patients at a certain stage of their treatment may require inpatient hospital treatment and that a hospital is a facility of the community.
But we agree entirely with the closing down and reorganisation of the big mental hospitals. The point I try to make is that the uncoordinated closing down of a central mental hospital does adversely affect the provision of services because there needs to be a facility for grossly disturbed patients, aggressive patients and also for long-stay patients who can't be managed in the community, even in high support hostels. I think the large hospitals have been closing down too rapidly and that there has been a fallout effect on our service as a result. And what is really more important is that the necessary money for the provision of adequate community services has not been provided.

With the NHS moving towards the idea of Trust hospitals, do you think the Irish experience in particular in the private sector offers British psychiatry any pointers as to what to expect?

I think that they probably could learn something from us because, as I understand it, the idea is that the hospitals will have to work efficiently, be selfsupporting and sell their services in effect. This is what we have been operating and, I believe, operating quite successfully.

In St Patrick's Hospital and this hospital, St John of God Hospital, we have developed an almost unique system - where we have the private and public sector working side by side, sharing the same facilities to a considerable extent but having separate budgets. Our community psychiatric service utilises beds here and pay us for them. They utilise our services beyond just the beds. While the public service consultant in charge of the case maintains clinical responsibility, the treatment programmes that are implemented are carried out by the staff employed by the hospital.

This cooperation is advantageous to both sectors. For example, for teaching purposes we have an extensive rotational training programme which encompasses in-patient training within this hospital, training within the community service, in liaison psychiatry at St Vincent's Hospital, which is the general teaching hospital, as well as the child psychiatric services and the mental handicap services run by the Order. So, at that level there is complete integration and cooperation.

I believe there is some misconception in the UK of the Irish version of 'private'. When I was a member of the Court of Electors of the College in the mid '70s 'private' was a very dirty word. Some of the members would go into spasm if the word was mentioned. Attitudes now seem to have changed. I have recently visited the Priory in Roehampton where Desmond Kelly is attempting to develop a programme similar to ours, that is to provide teaching and research within the framework of a private 
hospital. He is fortunate enough to have much better financial resources - their charges are much higher than ours, but the concept seems to be the same. I would imagine that something similar will have to develop in the Trust hospitals which are about to emerge.

We regard ourselves more as a voluntary hospital than a private hospital. What I aimed for when I came to this hospital was to transform it into the equivalent of a voluntary teaching hospital, and I think that I have largely succeeded in doing that. When my successor takes up the post of Medical Director I believe there will be yet further development.

\section{Why don't we have an Irish College of Psychiatry?}

That is an interesting topic. I have been very closely associated with the College since its foundation. Dr May Sullivan was the transitional Chairman and I was the first elected Chairman of the Irish Division following the establishment of the College. I believe that creating the College was a great achievement. I was conservative enough to have doubts about the wisdom of an independent College at the time, but I have no doubt that the right decision was made. It has transformed the status of psychiatry and it has been greatly beneficial to Ireland. The setting of standards of training for the membership examination and the accreditation system have been particularly important.

I believe that Irish psychiatry is now developing at such a pace, the standards of training are so good and we now have a thriving journal, the Irish Journal of Psychological Medicine, that soon we may have enough resources to be able to establish a body of our own. But I hope that when we do we will retain a very close association with the Royal College. We have been very well treated by the College and always had good relationships with the Presidents of the College. They have been very conscious of our particular needs and they have been satisfied that we, on our part, are producing well trained psychiatrists. On a personal level, the contact and support goes back to Martin Roth, who was an old friend of mine from the Crichton days and who, as already mentioned, had been on the Irish Commission for Mental Illness. He was very familiar with the Irish scene and, incidentally, the proud possessor of an Irish DPM.

Martin had a baptism of fire in the Irish Division, as I had. When the Irish Division was established I thought that we should be as good as any of the other specialities and have an official dinner in the College of Physicians, with important guests and so on. I thought it might be appropriate to start with the President of Ireland, who was Erskine Childers, who had always shown great interest in psychiatry and the psychological aspects of medicine. He kindly agreed to come along to our first annual dinner. Martin Roth came and we had other distinguished guests. President Childers gave his after dinner speech and sat down next to me and then proceeded to have a massive heart attack. The dinner came to a premature end. He was whisked off to the Mater Hospital, with us in pursuit, and died there a couple of hours later. So the Royal College of Psychiatrists was certainly put on the map. My photograph with President Childers was the last photograph of him and was on the front page of the Irish Times, and everybody learnt that there was such an organisation.

The following year Cearbhall O'Dalaigh was the President and I decided to invite him. He had been Chairman of the Irish National Council for Alcoholism beforehand and I had worked with him there. He accepted my invitation, but at 60 'clock that evening he rang me at home, he was a modest and informal man, to say that he was very sorry but that he thought that he should not come to dinner because the Tiede Herrema was still being held hostage by the IRA and he did not know whether there might be any break in the story.

He thought that if they had to locate him, it might be inappropriate that he should be seen to be wining and dining while this tragedy was being enacted. He kindly said that if we gave him a ring when it came to the coffee stage he would come in through a back door of the College and he would say a few words. He did so and when he was going out I asked him if, in view of the circumstances we could ask him to come the following year. He said he would be delighted and firmly promised me. At 6 o'clock on the night of the third dinner it was announced on the radio that he had resigned following a political impasse!

My term of office ended shortly afterwards. We have not had a President attend any of our functions since.

One of the things, I guess, when you began here that must be quite different to now is the influence of the church on psychological problems. The average priest in the 1950s, I suppose, was alcoholism counsellor and cognitive therapist all rolled into one.

Yes. When I came here one of the things that was so obviously lacking was the education of the public about psychiatry. We set about trying to do something about that, starting with various significant bodies such as the church. We commenced with the idea of running a course for hospital chaplains. I had a strong feeling that a good chaplain, spiritual advisor or pastoral worker, as they call it now, would be very important, particularly in a religiously orientated country like Ireland. The situation then was that some unfortunate curate was allocated to the mental hospital as he might be allocated to the local 
hospital and he had no interest apart from doing his priestly duties.

We started off with the idea of Chaplains, but no priest would declare himself to be a chaplain at that time because he might get stuck in that post and it would not be good for his career. So we broadened it out to the clergy in general and we ran a course in co-operation with Father Feichin O'Doherty, who was then Professor of Psychology in UCD. He was a friend of Leo Bartmeier and was favourably disposed towards psycho-analysis and other psycho-dynamic theories. We called the first course 'The Priest and Mental Health' and we produced the proceedings as a book which ran to a couple of editions and was published in the States as well. It was regarded as revolutionary although we took simple themes - the various mental illnesses, principles of mental health and so on. It was very positively accepted. We ran two more of these courses at yearly intervals. Many priests told me years afterwards that they had been a great help to them and had made them more understanding of the psychological problems of their parishioners.

The other group that I thought very important was nurses. Many were then poorly trained. They had their diplomas but they had little concept of modern psychiatry. I don't mean our nurses but the nurses in some of the mental hospitals in the country. They had no opportunity of going outside their own particular hospital for experience. So we started courses for nurses and again these had an enthusiastic reception. Many of these nurses had never been to another hospital and the whole idea of psychological handling of patients and, say, the effect of occupational therapy programmes were a revelation to them. It is now difficult to realise how primitive it was. Such courses were later incorporated into nurse training by An Bord Altranais and so we bowed out.

There was a double effect to all this in that while this work was educational it also helped to get the hospital recognised. One had to do an awful lot of talking to various bodies around the country, to GPs, the IMA, this society and that society, but it was worth it.

There has always been a particular association between St John of God Hospital and alcoholism. Why is this?

Interestingly enough this hospital was established over a hundred years ago and in one of the early adverts for it they specified that they would not take cases of inebriety. However, as you say, one way or another it became very much associated with alcoholism and more particularly with the idea of 'drunken priests'. When I was appointed Medical Director there was a suggestion that the hospital be turned into a 'proper hospital' and that it should get away from alcoholism - that we start with a clean sheet. I thought that would be a terrible mistake because I believed there was a great need for treatment of alcoholism and for public education on the subject.

I had experience with alcoholism in Crichton Royal and I was interested in the subject. I thought that we should do the opposite of that which was being proposed - that we should develop a clear-cut identifiable programme for patients suffering from alcoholism. Because of this I developed the Alcohol Unit within the psychiatric hospital as an identifiable place and we gradually developed more sophisticated programmes which are now accepted as orthodox treatment. I had a WHO fellowship back in 1961 to visit alcoholism centres in North America but I found that we were vastly ahead of them except for Toronto, which was excellent, and of course the Yale Centre for Studies on Alcohol.

When I was visiting the alcohol centre in Yale I had an amusing experience. I was having lunch with Mark Keller, the editor of the Journal of Studies on Alcohol and he said to me, "by the way, do you know a fellow named Davies; I think he is at a place called The Maudsley in London", and I replied "Oh yes - in fact he was Dean while I was working there". He said, "I've got this peculiar paper. He says that nine cases of alcoholism have got back to normal drinking - I find it very odd - is he reliable?" So I had to give a character reference for my former Dean, which rather pleased me and may have helped to start the controversy which waged for so many years.

We had several public and professional meetings on alcoholism. Then Norman Moore and I, with others, were involved in trying to set up an Irish National Council of Alcoholism. We had Marty Mann, The Director of the American National on Alcoholism, over to advise us. But we had difficulties the first time around - we couldn't get patrons, that is distinguished public figures who would be willing to be associated with alcoholism. Later we had another go. Norman was very persistent and it was largely due to his efforts that it got off the ground. This allowed us later to develop a training course for alcoholism councillors and to get official recognition for it. Following this services developed throughout the country, so quite a lot was achieved.

We still have an active treatment unit in the hospital organised by my colleague Dr Pat Tubridy. We don't go into the sterile argument of whether in-patient treatment is better than out-patient or whatever. I think that there are so many varieties of people with problems with alcohol that one particular population can be helped better on an in-patient basis, while others may cooperate on an out-patient basis. Certainly the population we deal with coming from all corners of Ireland seems to be helped by a 
28 day period of intensive group therapy followed by a lengthy after-care programme.

I think that as regards community services we're well developed compared to many places.

There is actually one thing that is better here than in Britain, which is that we do retain control of patients who are discharged from hospital. Patients in hostels stay within the psychiatric services. That is, I believe, not so in Britain, where I believe they come under local authority control.

Community services are still where the biggest need is. The private hospital will always be with us as long as it covers a wide section of the community. I believe that we should make it easier for people to utilise private facilities at some stage of their treatment and public services at other times. It isn't as though there's any ill-will in that regard. We were getting on very well, developing together and extending the co-operation between us but with the limited resources at present, there is a temptation to economise by eliminating from the community service patients who have utilised private resources.

There has been an extraordinary development of psychiatry over the past 30 years. This has been paralleled by the development of this hospital. This is where the Brothers come in. I would never have taken the gamble of putting up $\mathrm{f} 6$ million for a building modernisation of a psychiatric hospital at this stage. But it was an excellent move and it improved staff morale and the standard of patient care. Furthermore, patients are much less intimidated as are relatives visiting and so on - it is important.

Can you explain this point for a British reader - what would you say was the Brothers' motivation to put up f6 million?

They strive to meet a need and when they are meeting a need they want to do it as well as they possibly can. The main part of the hospital was up to 100 years old, so it was either put in the money or possibly close down, as it was falling behind modern expectations quite reasonable expectations. It needed investment to give the facilities that are needed for the delivery of effective psychiatric care.
One of the things that is very hard for the British to appreciate about the Irish situation is that up until about the early '70s any development in psychiatry came from St Patricks's and St John of God Hospital. The private sector was the leader in offering the quality of service, which is not too difficult to understand. But it was the same for teaching as well and all kinds of developments. We didn't develop these just simply as hospital based - we were concerned with improving standards throughout the country and a lot of the doctors who are in the psychiatric services throughout the country trained with us.

In more recent years, the Health Boards have become more conscious of their role in training and service developments and that, of course, has been brought home to them by the College.

But allied to the private or voluntary aspect of things, I suppose what a British reader might not appreciate is that an awful lot of social initiatives in Ireland have come from various religious Orders such as St John of God's.

Yes, that is a factor. The Order recognised, for example, that the country needed a child guidance service in the early ' 50 s and with the cooperation of the World Health Organisation, they set up the first.

Who actually would be the person to make that decision?

The Provincial. But his counsellors would fill him in on the necessary background. Of course, the ironic part about it is that when you become aware of a need and meet it the State tries to push you out. It's hard to explain why you should want to stay in - why not let the State take it. Unfortunately experience shows that often after services are started, are going well, have good morale and good facilities, and are working, the State takes over and you find things just sink to the lowest common denominator.

Surely all this talk of the State taking over things is changing now?

I hope so. 